\title{
Intra-urban differences in breast cancer mortality: a study from the city of Malmö in Sweden
}

Jonas Manjer, Göran Berglund, Lennart Bondesson, Jens Peter Garne, Lars Janzon, Anna Lindgren, Janne Malina, Sophia Matson

\begin{abstract}
Study objective-To assess whether in an urban population stage at breast cancer diagnosis is related to area of living and to what extent intra-urban differences in breast cancer mortality are related to incidence respectively stage at diagnosis.

Design-National registries were used to identify cases. Mortality in 17 residential areas was studied in relation to incidence and stage distribution using linear regression analysis. Areas with high and low breast cancer mortality, incidence and proportion of stage II+ tumours at diagnosis were also compared in terms of their sociodemographic profile.
\end{abstract}

Setting-City of Malmö in southern Sweden.

Patients-The 1675 incident breast cancer cases and 448 deaths that occurred in women above 45 years of age in Malmö 1986-96.

Main results-Average annual age standardised breast cancer mortality ranged between residential areas, from $35 / 10^{5}$ to $107 / 10^{5}, p=0.04$. Mortality of breast cancer was not correlated to incidence, $r=0.22$, $\mathbf{p}=0.39$. The ratio of stage $\mathrm{II}+/ 0-\mathrm{I}$ cancer incidence varied between areas from 0.45 to 1.99 and was significantly correlated to breast cancer mortality, $r=0.53, p=0.03$. Areas with high proportion of stage II+ cancers and high mortality/incidence ratio were characterised by a high proportion of residentials receiving income support, being foreigners and current smokers.

Conclusions-Within this urban population there were marked differences in breast cancer mortality between residential areas. Stage at diagnosis, but not incidence, contributed to the pattern of mortality. Areas with high proportion of stage II+ tumours differed unfavourably in several sociodemographic aspects from the city average.

(F Epidemiol Community Health 2000;54:279-285)

Clinical stage at breast cancer diagnosis ranges from in situ carcinomas to large invasive tumours with local and distant metastasis. This wide range has many contributing causes of which patient's delay is one. ${ }^{1}$ The epidemiological features associated with late diagnosis are however not well known.

The City of Malmö is located in areas of Sweden that have the highest incidence and mortality from cancer. ${ }^{2}$ The approximately 250000 inhabitants live in 18 administrative units, which in terms of their socio- demographic profile and their morbidity and mortality patterns are very different. ${ }^{3}$ From 1976 to 1990 , a random sample of $50 \%$ of all women 45-69 years of age received invitation to mammography screening examination. ${ }^{4}$ The controlled design continued until 1990. Since then all women 50-69 years of age are regularly invited. All with breast cancer are admitted to Malmö University Hospital. Treatment procedures have been for many years standardised according to stage of disease. ${ }^{5}$ Health surveys have shown that within the city there are marked differences of the age standardised breast cancer mortality. ${ }^{3}$ To what extent this variation is related to incidence respectively stage at diagnosis has not been elucidated. Publicised studies on geographical differences in breast cancer mortality indicate that both explanations may contribute. ${ }^{67}$

The objective of this study has been to assess whether in this urban population stage at diagnosis is related to area of living and to what extent intra-urban differences in breast cancer mortality is related to incidence respectively stage at diagnosis.

\section{Methods}

Since 1986 it has been possible, by a specific code added to the civil registration number, to assign patients to one of 18 residential areas in Malmö. Because of the small population in the "harbour" area, this was excluded in the analysis. The study was limited to breast cancer in women above 45 years of age.

BREAST CANCER MORTALITY, INCIDENCE AND STAGE AT DIAGNOSIS

The National Causes of Death Registry identified 499 women who between 1986-1996 had died from breast cancer in Malmö. There were 20 women who could not be assigned to a specific area (mean age at death: 86.9 years, $\mathrm{SD}=7.5$ ), this left 479 cases (mean age at death: 68.5 years, $S D=14.3$ ). Those above 45 years of age, in total 448 women, were used to calculate average annual age standardised breast cancer mortality in each area.

Between 1986-1996 in Malmö, 2089 women, retrieved from the Regional Tumour Registry for Southern Sweden, were diagnosed with breast cancer, invasive or in situ. Of these, 266 cases could not be assigned to a specific area (mean age: 64.7 years, $S D=16.0$ ).

Of the remaining 1823 cases (mean age at diagnosis: 65.2 years, $S D=13.0$ ), those diagnosed after 45 years of age, in total 1675 women, were included in the analysis.

From 1986 to 1996,250 of these died in Malmö. Of these, 20 had changed their address since diagnosis. 


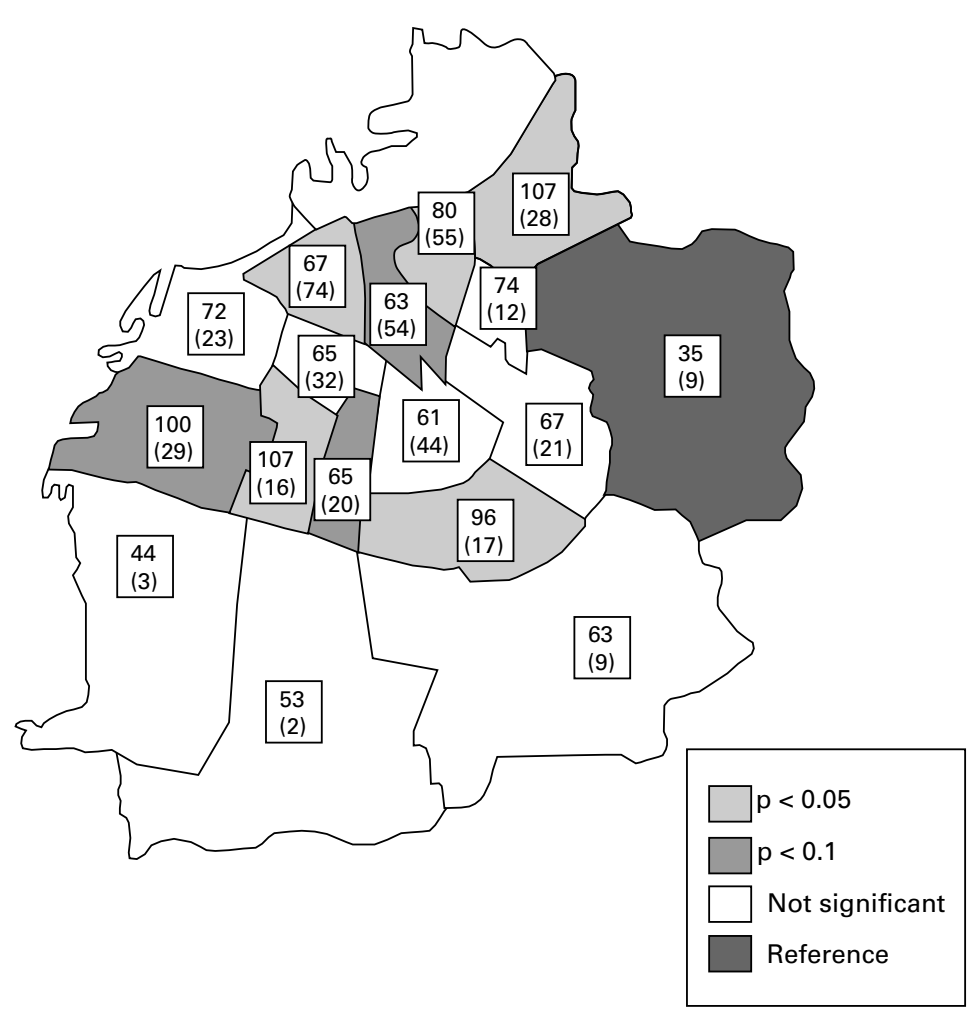

Figure 1 Average annual age standardised mortality of breast cancer $/ 10^{5}$ person years, total number of cases within parentheses. $p$ Values are related to comparision with the area with the lowest mortality.
Table 1 Number of areas according to stage at diagnosis

\begin{tabular}{ll}
\hline Age standardised ratio of stage II+/I tumours & Number of areas \\
\hline$<0.60$ & 2 \\
$0.60-0.79$ & 4 \\
$0.80-0.99$ & 3 \\
$1.00-1.19$ & 3 \\
$20-1.39$ & 3 \\
$\geqslant 1.40$ & 2 \\
\hline
\end{tabular}

of Planning and Statistics at Malmö City Council. ${ }^{9}$ Data on mean body mass index (BMI) and smoking habits in the 17 areas were obtained from a mailed questionnaire survey carried out in $1994 .^{10}$

\section{STATISTICAL METHODS}

Average annual crude breast cancer mortality, incidence and stage specific incidences were calculated/100 000 person years. Pearson's correlation coefficients (two tailed test) were used to explore to what extent these measurements were affected by the population mean age in different areas.

To adjust for differences in age distribution between areas, average annual age standardised breast cancer mortality, incidence and stage specific incidence together with mortality from all other causes in women above 45 years of age were calculated for each area using direct standardisation. The female population above 45 years of age in Malmö 1991 was used as standard population.

Intra-urban differences in average annual age standardised breast cancer mortality, incidence and stage specific incidence were assessed by the Kruskal-Wallis test. The Mann-Whitney test was used to locate statistically significant differences between breast cancer mortality in each residential area as compared with the area that had the lowest rate. This and all other tests were two tailed and a $\mathrm{p}$ value $\leqslant 0.05$ was regarded statistically significant.

Linear regression analysis was used to investigate to what extent geographical variation in mortality reflect differences in incidence. To study the relation between mortality and stage at diagnosis, the ratio between age standardised stage II+ and stage 0 -I incidence for the period 1986-91 was compared with the corresponding average annual age standardised breast cancer mortality using linear regression analysis. Finally, both incidence and stage at diagnosis were entered as covariates into a multiple linear regression analysis with mortality as dependent variable. Pearson's correlation coefficient $(r)$ was used to study the correlation between breast cancer mortality and mortality from all other causes in women above 45 years of age.

Sociodemographic factors, BMI and smoking habits in the four areas with the highest and the lowest incidences, case-fatality rates (mortality/incidence) and ratios of stage II+ and stage $0-I$ incidence were compared with the city average, which was set to 100 . Associations were also expressed in terms of Pearson's correlation coefficient. 


\section{Results}

BREAST CANCER MORTALITY, INCIDENCE, STAGE AT DIAGNOSIS AND POPULATION MEAN AGE Average annual crude mortality of breast cancer ranged between areas from $28 / 10^{5}$ to
$111 / 10^{5}$. Corresponding incidence varied between $204 / 10^{5}-315 / 10^{5}$. The ratio of crude stage II+/ stage 0 -I incidence was in the range $0.30-1.71$. Population mean age was statistically significantly related to mortality, $r=0.62$,

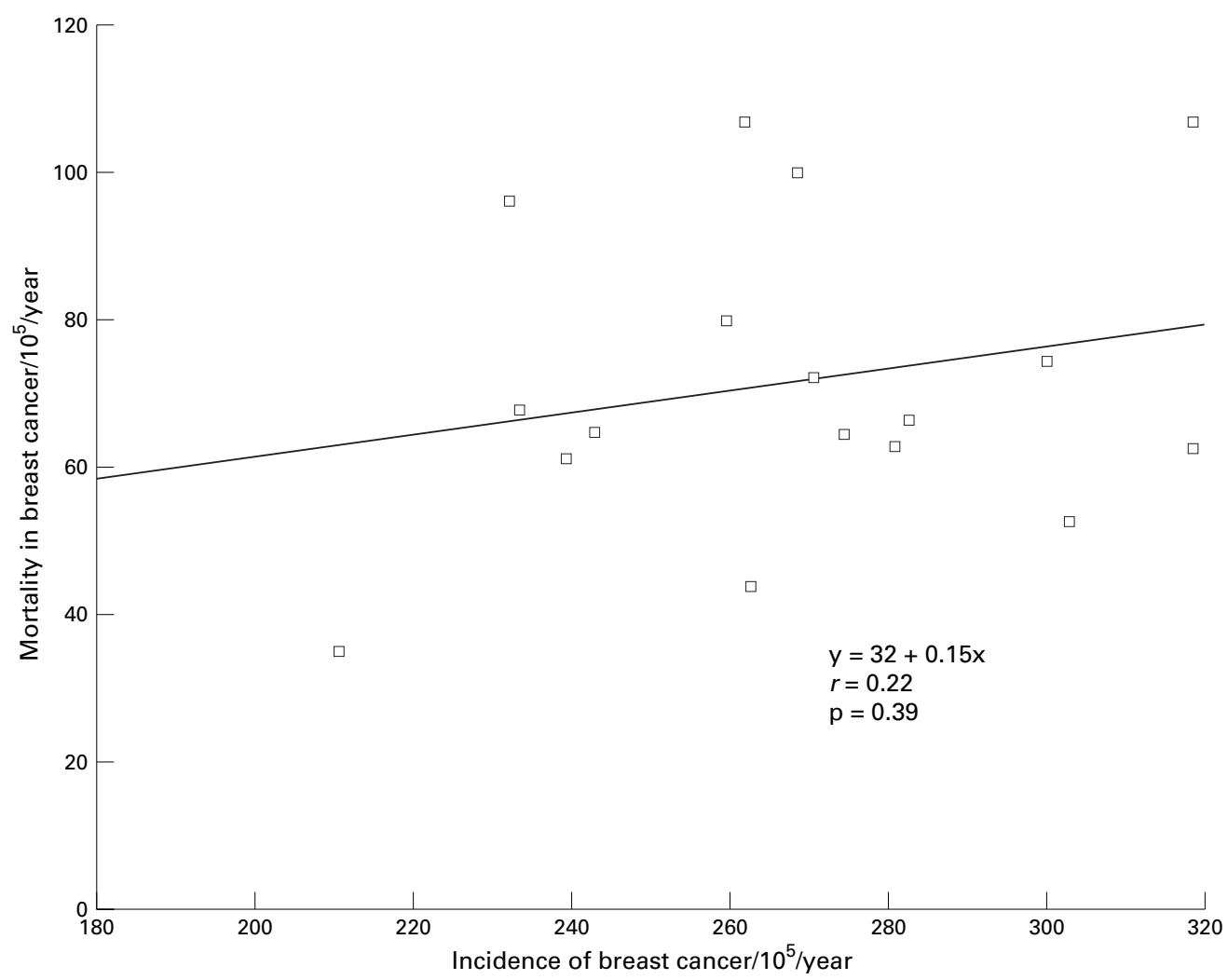

Figure 2 Average annual age standardised mortality in relation to incidence of breast cancer in the 17 areas.

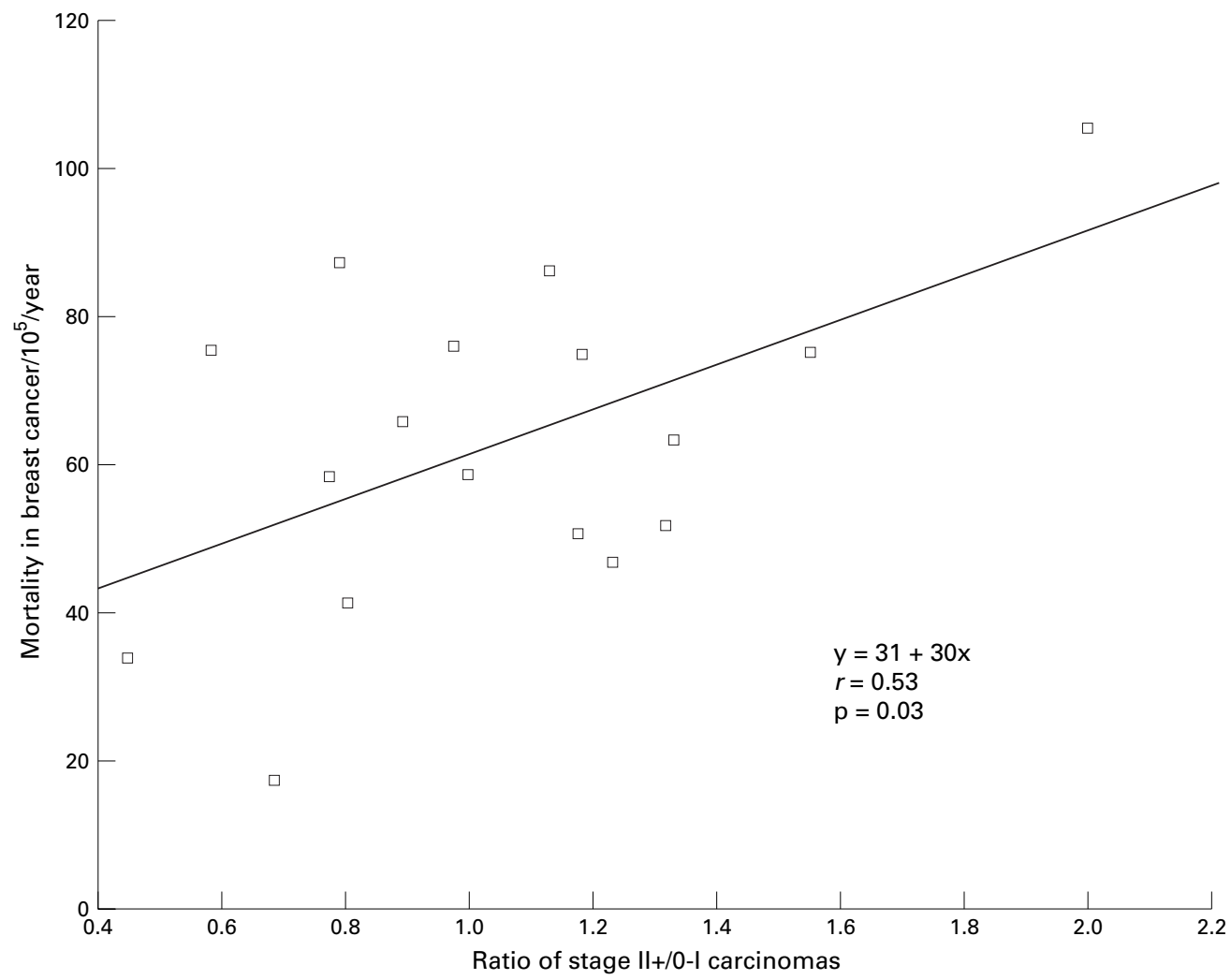

Figure 3 Average annual age standardised mortality in relation to the ratio between stage II+/0-I carcinomas in the 17 areas. 
Table 2 Relation between breast cancer and socioeconomic and lifestyle factors assessed by Pearson's correlation coefficient (r)

\begin{tabular}{|c|c|c|c|c|c|c|c|}
\hline \multirow[b]{2}{*}{ Socioeconomic, lifestyle factors } & \multirow[b]{2}{*}{ Mean in Malmö } & \multicolumn{2}{|c|}{ Ratio stage $I I+/ 0-I$} & \multicolumn{2}{|c|}{ Incidence $/ 10^{5}$} & \multicolumn{2}{|c|}{ Case-fatality rate (\%) } \\
\hline & & $r$ & $p$ & $r$ & $p$ & $r$ & $p$ \\
\hline Income (SEK) & 156005 & -0.48 & $0.05^{\star}$ & 0.03 & 0.91 & -0.43 & 0.08 \\
\hline Income support (\%) & 11 & 0.38 & 0.13 & -0.16 & 0.54 & 0.51 & $0.04^{\star}$ \\
\hline Registered unemployment (\%) & 4 & 0.66 & $0.004^{\star}$ & -0.10 & 0.70 & 0.57 & $0.02^{\star}$ \\
\hline Low educational level (\%) & 40 & 0.08 & 0.75 & -0.19 & 0.47 & 0.19 & 0.48 \\
\hline Manual workers (\%) & 47 & 0.21 & 0.41 & -0.04 & 0.89 & 0.35 & 0.16 \\
\hline Foreign background (\%) & 22 & 0.26 & 0.31 & -0.16 & 0.54 & 0.41 & 0.10 \\
\hline Migration (\%) & 15 & 0.35 & 0.18 & 0.08 & 0.76 & 0.44 & 0.08 \\
\hline $\mathrm{BMI}\left(\mathrm{kg} / \mathrm{m}^{2}\right)$ & 24.5 & -0.08 & 0.76 & -0.19 & 0.45 & -0.07 & 0.79 \\
\hline Current smokers (\%) & 31 & 0.51 & $0.04^{\star}$ & -0.01 & 0.97 & 0.49 & $0.05^{\star}$ \\
\hline Former smokers (\%) & 25 & -0.52 & $0.03^{\star}$ & 0.18 & 0.49 & -0.50 & $0.04^{\star}$ \\
\hline
\end{tabular}

$\star_{\mathrm{p}} \leqslant 0.05$.

$\mathrm{p}<0.01$, and to the ratio of crude stage $\mathrm{II}+/ \mathrm{I}$ incidence, $r=0.48, p=0.05$, but not to crude incidence, $r=0.35, \mathrm{p}=0.16$.

BREAST CANCER MORTALITY, INCIDENCE AND STAGE AT DIAGNOSIS

Average annual age standardised mortality of breast cancer ranged between areas from $35 / 10^{5}$ to $107 / 10^{5}, p=0.04$, mean: $69.9 / 10^{5}$, figure 1 . Breast cancer mortality was in five areas significantly higher than in the reference area. When the analysis was restricted to the 250 deaths that had been diagnosed during the period 1986-96, the range between areas was $17 / 10^{5}-64 / 10^{5}, \mathrm{p}=0.04$, mean: $38 / 10^{5}$, The mortality pattern in this analysis was very similar to the full model, Pearsons's correlation coefficient: $0.77, \mathrm{p}<0.001$ (two tailed test). The correlation between mortality from breast cancer with that from all other causes in women above 45 years of age was $0.36, p=0.16$.
Average annual age standardised incidence ranged between areas from $211 / 10^{5}$ to $318 / 10^{5}$, $\mathrm{p}=0.90$, mean: $265 / 10^{5}$, figure 2 , age standardised incidence of stage 0 -I cancers from $70 / 10^{5}$ to $163 / 10^{5}, \mathrm{p}=0.84$, mean: $127 / 10^{5}$, and for stage II+ cancer from $72 / 10^{5}$ to $165 / 10^{5}$, $\mathrm{p}=0.34$, mean: $132 / 10^{5}$. The ratio of age standardised incidence of stage II+ and stage $0-\mathrm{I}$ cancers varied between areas from 0.45 to 1.99, mean: 1.08 , table 1 .

Average annual age standardised mortality, incidence and the ratio between stage II+ and stage I breast cancer incidence, all had distributions similar to normality.

The correlation between age standardised breast cancer mortality and incidence in the areas was $0.22, p=0.39$, figure 2 . The correlation between age standardised breast cancer mortality and the ratio of age standardised stage II+/0-I breast cancer incidence in the areas was $0.53, p=0.03$, figure 3 . The multiple

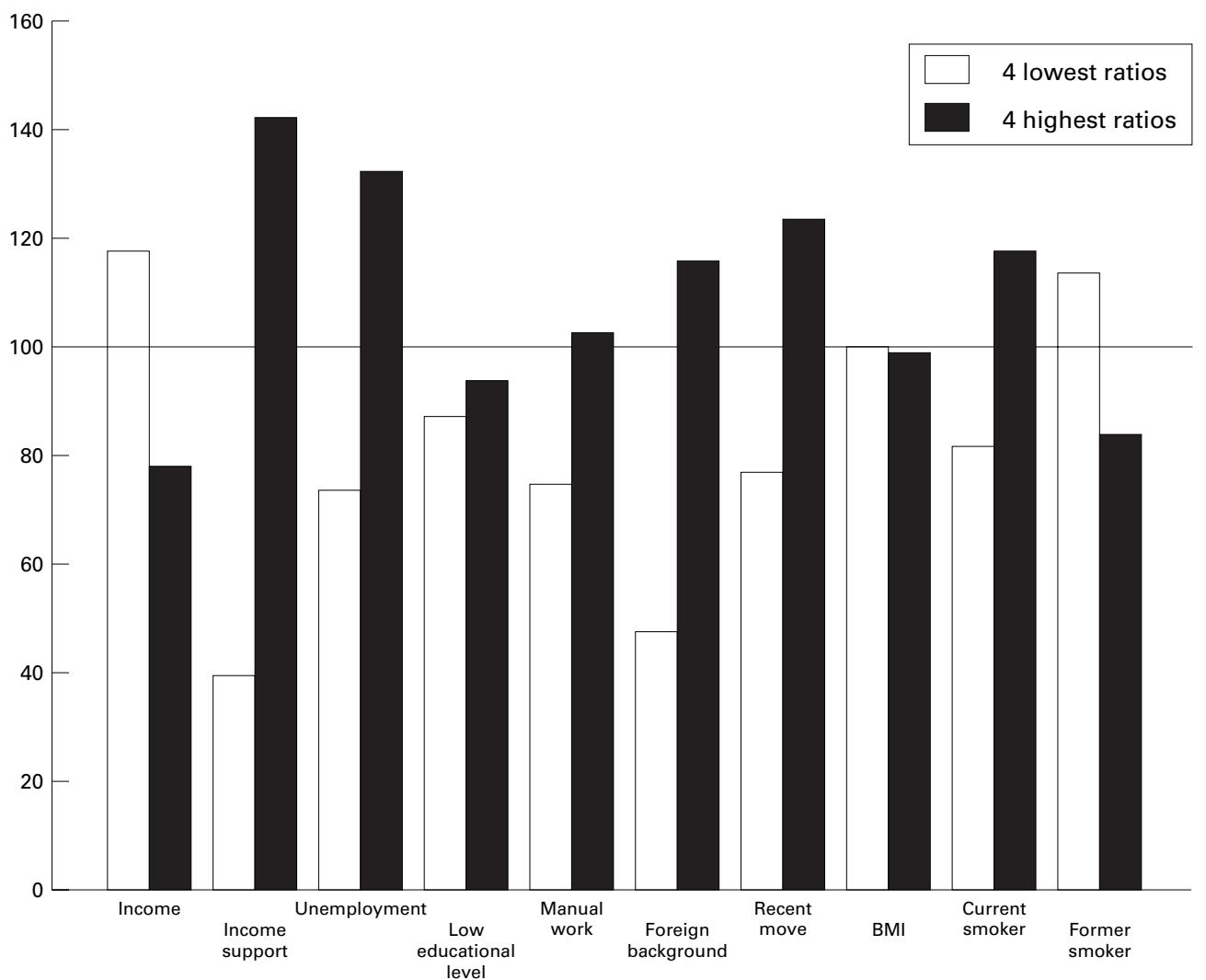

Figure 4 Different sociodemographic circumstances, smoking and BMI in the four areas with highest and the four with lowest ratios of stage $I I+/ 0-I$ carcinomas. $100=$ city average. 


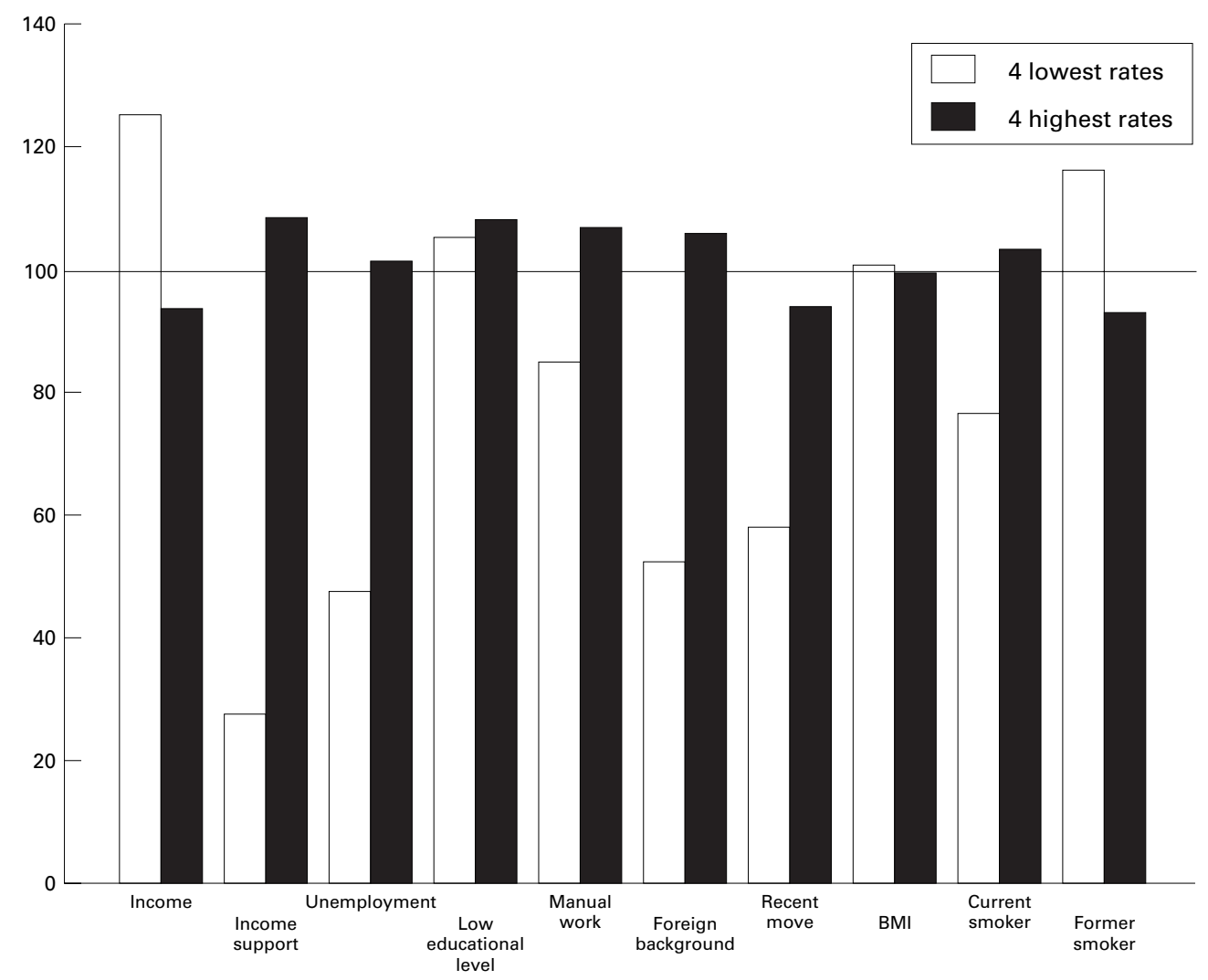

Figure 5 Different sociodemographic circumstances, smoking and BMI in the four areas with highest and the four with lowest case-fatality rates. $100=$ city average.

regression analysis, which included both incidence and stage, yielded an $r$ value of 0.53 and $p$ values of 0.86 for incidence and 0.03 for the ratio of age standardised stage II+/0-I incidence. The results remained unchanged after exclusion of cases with in situ carcinoma (data not shown).

\section{STAGE AT DIAGNOSIS, INCIDENCE AND CASE-FATALITY RATE IN RELATION TO RESIDENTIAL AREAS}

The four areas with the highest age standardised stage II $+/ 0-\mathrm{I}$ incidence ratios deviated in several aspects from the city average. People in these areas had a lower average income, a higher proportion received income support, many were unemployed, many were foreigners, more people had changed their address in the past year, a higher percentage were current smokers and fewer were former smokers, figure 4 . The ratio of stage $\mathrm{II}+$ /stage $0-\mathrm{I}$ incidence was significantly higher in areas with low average income, a high unemployment rate and in areas with a high proportion of current and former smokers, table 2.

The four areas with the highest incidences had, compared with the city average, a lower percentage of people receiving income support.

The four areas with the highest case-fatality rate had, compared with the city average, a lower average income, a higher proportion receiving income support and a higher percentage of manual workers and foreigners, figure 5 . In the four areas with the lowest case-fatality rate there were, compared with the city average, a lower unemployment rate, few current smokers and many former smokers. There was statistically significant correlation between case-fatality rate and income support, unemployment rate and the proportions of current and former smokers, table 2 .

\section{Discussion}

Mammography breast cancer screening started in Malmö in 1977 as a controlled trial. After the publication of the study in $1988^{4}$ it was decided that all women who were between 50 and 69 years of age should regularly be invited to screening. ${ }^{5}$ Date and order for invitation to screening had no relation to area of living. Women who were invited to the screening trial were randomly chosen on the basis of their 10 digit civil registration number. ${ }^{4}$ It can hence be concluded that circumstances for early detection and treatment have developed in a similar fashion in all residential areas.

Yet, even in the presence of a general breast cancer screening programme, there is substantial variation within the population with regard to stage at diagnosis. Advanced stage at diagnosis in an area was positively correlated with population mean age. However, the differences in stage at diagnosis remained after age standardisation. Areas with a high age adjusted ratio of stage II+/stage I incidence differed unfavourably in several sociodemographic aspects from the city average. It has been shown in other studies that low socioeconomic status is associated with more advanced tumour stage at diagnosis ${ }^{11}{ }^{12}$ because of the long delay for the patient or low participation in mammography screening. ${ }^{13-15}$ 
Whether the socioeconomic environment in itself - that is, independent of the person's own socioeconomic circumstances, has any influence on the probability of early detection and participation in mammographic screening remains to be evaluated.

Several studies have investigated the question whether geographical differences in breast cancer mortality reflect differences in incidence or case-fatality rate. ${ }^{6}$ In this study, incidence did not explain intra-urban differences in breast cancer mortality. It should however be pointed out that detection and treatment of in situ carcinoma, which during the first 10 years of the mammography trial constituted $15 \%$ of all breast cancer tumours, ${ }^{4}$ may have confounded the incidence.

Stage at diagnosis explained $28 \%(r=0.53)$ of the variance in breast cancer mortality between areas. This is in line with a study by Goodwin and colleagues ${ }^{7}$ on breast cancer mortality in relation to survival. Whether other tumour characteristics - that is, histopathology, differentiation and oestrogen receptor status ${ }^{5}$ - may influence pattern of disease remains to be evaluated.

Experimental and observational studies have shown that survival is related to adjuvant radiotherapy and chemotherapy. ${ }^{5}$ In Malmö everyone with breast cancer is admitted to the same hospital where therapeutic procedures have followed standardised guidelines during the study period. ${ }^{5}$ It is therefore unlikely that differences in survival are related to treatment.

Some studies indicate that survival may be influenced by other factors than treatment and stage at diagnosis. Smoking was associated with poor survival in a study by Yu and colleagues. ${ }^{16}$ High intake of dietary fat, ${ }^{17}$ obesity ${ }^{17}{ }^{18}$ and poor social support ${ }^{19}$ has similarly been associated with poor survival. These circumstances have in several studies been found to be more common in groups with low socioeconomic status. $^{20-23}$ Whether in fact the sociodemographic environment in itself has any influence on long term survival remains however to be evaluated in future patient cohort studies.

Some potential biases have to be considered. Residential area was defined at diagnosis. A relevant question is therefore whether patients remained in that same area. No information is available to assess the magnitude of migration between residential areas among cases that survived. Of the incident cases that died, less than $10 \%$ had changed residential area from diagnosis to death. Another problem concerns cases that could not be assigned to a specific residential area. Most of them were old women who because of chronic diseases were living in nursing homes. Considering the comparatively small number it is not likely that any major bias was introduced.

Competing mortality is another relevant issue; that is, high breast cancer mortality in an area may simply reflect low mortality from other causes. High mortality from breast cancer was not associated with low mortality from other causes of death. Thus, we conclude that differences in breast cancer mortality were
KEY POINTS

- Within an urban population there may exist marked differences in breast cancer mortality between residential areas.

- Stage at diagnosis, but not incidence, seem to be the major explanation to the pattern of mortality.

- Areas with a high proportion of stage II+ tumours and a high case-fatality rate differed in terms of their sociodemographic profile unfavourably from the city average.

unlikely to have been caused by competing mortality.

In this urban population substantial differences were observed in breast cancer mortality between residential areas. Stage at diagnosis seems more closely related than incidence to such differences. A number of sociodemographic circumstances were associated with advanced disease, though the relation of socioeconomic environment with early detection and survival remains to be clarified.

The authors wish to thank the following: Mrs Birgitta Malmström, Malmö University Hospital, who provided data from the hospital records. Mr Anders Ardmar and Mr Henry Lindelöf, The Unit of Planning and Statistics at Malmö City Council, who kindly submitted data on sociodemographic factors. Dr Martin Lindström, Malmö University Hospital, author of "The Health Situation in Malmö" from which data on smoking and BMI were obtained.

Funding: the first author of this paper is employed as a $\mathrm{PhD}$ student at the Department of Community Medicine, Malmö University Hospital. No other funding have been given to the authors.

Conflicts of interest: none.

1 Afzelius P, Zedeler K, Sommer H, et al. Patient's and doctor's delay in primary breast cancer. Acta Oncol 1994;33:345-51.

2 The National Board of Health and Welfare. Yearbook of Health and Medical Care 1997. Stockholm: The National Health and Medical Care 1997. Stocks

3 Nilsson A, Hanson B S, Isacsson S-O. Public Health Report The City of Malmö 1991. [in Swedish]. Malmö: Department of Community Medicine, Malmö University Hospital, 991.

4 Andersson I, Aspegren K, Janzon L, et al. Mammographic screening and mortality from breast cancer: the Malmö Mammographic Screening Trial. BMF 1988;297:943-8.

5 Garne JP. Invasive breast cancer in Malmö 1961-1992-An epidemiological study, Malmö, Sweden. [PhD Thesis]. Lund: Lund University, 1996.

6 Sturgeon S R, Schairer C, Gail M, et al. Geographic variations in mortality from breast cancer among white women in the United States. F Natl Cancer Inst 1995;87: 1846-53.

7 Goodwin JS, Freeman JL, Freeman D, et al. Geographic variations in breast cancer mortality: do higher rates imply elevated incidence or poorer survival. Am $\mathcal{f}$ Public Health 1998;88:458-60.

8 American Joint Committee on Cancer. Manual for staging of American Joint Committee on Cancer. Manual for staging
cancer. 3rd ed. Philadelphia: J B Lippincott, 1988:27.

9 The Unit of Planning and Statistics, Malmö City Council. The Unit of Planning and Statistics, Malmö City Council.
Areas statistics for Malmö 1991-96. [in Swedish]. Malmö, Sweden: The Unit of Planning and Statistics, Malmö City Council, 1991-96.

10 Lindström M, Bexell A, Hanson BS, et al. The health situation in Malmö: report from a mailed questionnaire survey, Spring 1994 [in Swedish]. Malmö, Sweden: Department of Community Medicine, Malmö University Hospital, 1995.

11 Farley TA, Flannery JT. Late-stage diagnosis of breast cancer in women of lower socioeconomic status: public health implications. Am f Public Health 1989;79:1508-12.

12 Schrijvers CTM, Mackenbach JP, Lutz J-M, et al. Deprivation and survival from breast cancer. Br F Cancer 1995;72: $738-43$.

13 Huguley CM Jr, Brown RL, Greenberg RS, et al. Breast selfexamination and survival from breast cancer. Cancer 1988; 62:1389-96.

14 Hurley SF, Huggins RM, Jolley DJ, et al. Recruitment activities and sociodemographic factors that predict attendance at a mammographic screening program. $A m \mathcal{F}$ Public Health 1994;84:1655-8. 
15 Wells BL, Horm JW. Targeting the underserved for breast and cervical cancer screening: the utility of ecological
analysis using the National Health Interview Survey. Am $\mathcal{F}$ analysis using the National Health

16 Yu G-P, Ostroff JS, Zhang Z-F, et al. Smoking history and cancer patient survival: a hospital cancer registry study Cancer Detect Prev 1997;21:497-509.

17 Zhang S, Folsom AR, Sellers TA, et al. Better breast cancer survival for postmenopausal women who are less overweight and eat less fat. Cancer 1995;76:275-83.

18 Vatten LJ, Foss OP, Kvinnsland S. Overall survival of breast cancer patients in relation to preclinically determined total serum cholesterol, body mass index, height, and cigarette smoking: a population-based study. Eur f Cancer 1991;27: 641-6.
19 Maunsell E, Brisson J, Deschenes L. Social support and survival among women with breast cancer. Cancer 1995;76: 631-7.

20 Rosén M, Hanning M, Wall S. Changing smoking habits in Sweden: towards better health, but not for all. Int $\mathcal{F}$ Epidemiol 1990;19:316-22.

21 Mackenbach JP. Socioeconomic health differences in The Netherlands: a review of recent empirical findings. Soc $S c i$ Med 1992; 34:213-26.

22 Smith AM, Owen N. Associations of social status and health-related beliefs with dietary fat and fiber densities. Prev Med 1992;21:735-45.

23 Stunkard AJ, Sørensen TIA. Obesity and socioeconomic status-a complex relation. $N$ Engl f Med 1993;329:1036-7. 